\title{
Low-Quality Domestic Automobiles Continue to Threaten Lives in Iran: Economic Instability as the Potential Contributor
}

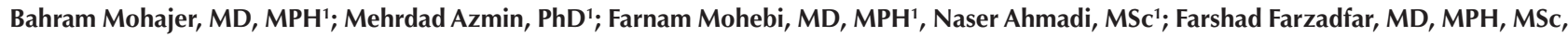 \\ DSc $^{1,2^{*}}$ \\ ${ }^{1}$ Non-Communicable Diseases Research Center, Endocrinology and Metabolism Population Sciences Institute, Tehran University of Medical \\ Sciences, Tehran, Iran \\ ${ }^{2}$ Endocrinology and Metabolism Research Center, Endocrinology and Metabolism Clinical Sciences Institute, Tehran University of Medical \\ Sciences, Tehran, Iran
}

\section{Dear Editor,}

With the $16^{\text {th }}$ largest automobile industry worldwide, ${ }^{1}$ Iran is confronted with the $3^{\text {rd }}$ highest rate of road traffic mortality among middle-income countries at 32.1 deaths per $100000^{2}$ as a major public health concern. However, there is no international report showing that its domestically designed and produced passenger vehicles comply with global safety regulations including frontal impact, electronic stability control, and pedestrian protection. ${ }^{3}$ The most affordable of these is the Saipa Pride, a variant of the 1986 Ford Festiva subcompact city car, the price of which has almost quadrupled in the last two years. Saipa Pride accounts for more than 6 million of total 20 million passenger vehicles in Iran and has the lowest safety scores in domestic evaluations. ${ }^{4}$

We collected road accident data from Iran Road Maintenance and Safety Organization, containing all inter-city road accidents leading to at least one at-thescene death in 2017 ( $\mathrm{n}=5801)$. We excluded 1180 events involving non-4-wheel vehicles including inter-city buses or motorcycles. Accidents caused an average of $1.28 \pm 0.72$ deaths and $0.85 \pm 1.23$ non-fatal injuries. Generalized loglink Poisson regression adjusted for the total number of cars, resulted in near $9 \%$ of increase in injuries with each more Pride involved in the accident compared to other domestic cars (incident risk ratio or IRR $=1.08$, CI: $1.02-$ 1.16). This increases to $21 \%$ when comparing Pride to all other domestic or imported 4-wheel vehicles (IRR = 1.21, CI: 1.14-1.28). While our data have limitations like unavailability of records of non-fatal accidents, our results show that being involved in an accident in Saipa Pride, as the most accessible automobile in Iran, is likely to result in higher incidents of road traffic injuries at the accident scene.

Trump's announcement of the US's withdrawal from the joint comprehensive plan of action and signing of a presidential memorandum to institute the highest level of sanctions on Iran $^{5}$ was marked by the unprecedented devaluation of the Iranian Rial to a tenth of its value against the US dollar during the past two years. This led to inflation in prices for both imported and domestically produced goods. On the other hand, the exit of European car manufacturers over US sanctions and continued inflation may result in further reduction of production quality and purchasing power and consequently, increase the demand for cheaper domestic vehicles. This is of special significance for younger individuals and families, who on average have lower income and a higher risk of exposure to traffic injuries, ${ }^{6}$ seeking to own their first vehicle. We are thus likely to see increased mortality and morbidity from road accidents in Iran as an indirect consequence of the continuation of economic instability.

\begin{abstract}
Authors' Contribution
$B M$ and $M A$ contributed to data gathering, $B M, F M, N A$, and $M A$ have conducted the data analysis, BM, FM, MA, NA, and FF have drafted and finalized the manuscript. FF and BM have done the conceptual design of the study.
\end{abstract}

\section{Conflict of Interest Disclosures}

None.

Ethical Statement

This project has been ethically approved by the National Institute of Medical Research Development ethics code: IR.NIMAD. REC.1394.016.

\section{Acknowledgments}

The authors would like to thank the National Institute of Medical Research Development (NIMAD) for funding this project by grant No.940576.

\section{References}

1. IOCA. International Organization of Motor Vehicle Manufacturers (OICA) 2017 production statistics. 2017:1.

2. World Health Organization (WHO). WHO Report 2015: Data 
tables. 2015. Available from: http://www.who.int/violence injury_prevention/road_safety_status/2015/GSRRS2015_data/ en. Accessed October 31, 2018.

3. Wilman M, Bax B. The automotive industry in Iran: A critical analysis. In: International Business and Management. Emerald Group Publishing Limited, 2015:57-74.

4. ISQI. Iran Standard and Quality Co. 2019. Available from: https://isqi.co.ir/. Accessed April 3, 2019.

5. Arms control association. Timeline of Nuclear Diplomacy With
Iran. Arms Control Assoc. 2018. Available from: https://www. armscontrol.org/factsheet/Timeline-of-Nuclear-DiplomacyWith-Iran\#2018. Accessed Oct 31, 2018.

6. Sengoelge M, Laflamme L, El-Khatib Z. Ecological study of road traffic injuries in the eastern Mediterranean region: country economic level, road user category and gender perspectives. BMC Public Health. 2018;18(1):236. doi: 10.1186/s12889018-5150-1.

Received: May 27, 2020, Accepted: September 6, 2020, ePublished: November 1, 2020

Cite this article as: Mohajer B, Azmin M, Mohebi F, Ahmadi N, Farzadfar F. Low-quality domestic automobiles continue to threaten lives in Iran: economic instability as the potential contributor. Arch Iran Med. 2020;23(11):764-765. doi: 10.34172/aim.2020.101.

(c) (1) (C) 2020 The Author(s). This is an open-access article distributed under the terms of the Creative Commons Attribution License (http://creativecommons. org/licenses/by/4.0), which permits unrestricted use, distribution, and reproduction in any medium, provided the original work is properly cited. 